\title{
BIOJET FUEL PRODUCTION BASED ON METHYL ESTER CHAIN OF COOKING OIL WASTEUTILIZING BUBBLE OZONOLYSIS REACTOR
}

\author{
Wahyuningsih $^{1}$, Sri Utami Handayani ${ }^{2}$, Sutrisno ${ }^{2}$, Didik Ariwibowo ${ }^{2}$, \\ Mohammad Endy Yulianto ${ }^{1}$, Farika T Putri ${ }^{2, *}$ and Indah Hartati ${ }^{3}$ \\ ${ }^{1}$ Chemical EngineeringDepartment, Vocational School, \\ Diponegoro University, 50275, Indonesia \\ ${ }^{2}$ Mechanical Engineering Department, Vocational School, \\ Diponegoro University, 50275, Indonesia \\ ${ }^{3}$ Chemical Engineering Department, Faculty of Engineering, \\ Wahid Hasyim University, 50236, Indonesia \\ *E-mail : farikatonoputri@gmail.com
}

\begin{abstract}
Development of renewable bio jet fuels is increasing due to the depletion of fossil fuel reserve. Biojet fuel can be generated using ozonolysis reaction which the unsaturated carbon-carbon bond is cleavaged and replaced with an oxygen double bond. The medium carbon chains of methyl ester that have a similar characteristic with the bio-jet fuel can be produced from the cleavage of a long chain of the methyl ester of biodiesel. The purpose of this research was to investigate the cooking oil waste ozonolysis in a bubble reactor, followed by the free fatty acid esterification process towards the ozonolysis product. The ozonolysis was conducted in a bubbling ozonolysis reactor and the reaction was performed by varied the catalyst concentration and the ozonolysis duration. The product was tested for its density and kinematic viscosity. The experiment results showed that the esterification products were met the density and kinematic viscosity criteria of the commercial bio jet fuel which the density should be in the range of $0.775-0.840 \mathrm{~g} / \mathrm{ml}$ for Jet A-1. The density of the ozonized product conducted at 2 and 3 hours with $3 \%$ of catalyst addition was able to give a product having a density of 0.825 and 0.8 , respectively. Meanwhile, the density of the esterified of the ozonized product of 1-3 hours ozonolysis and 3\% catalyst addition were in the range of 0.738 and 0.826 .
\end{abstract}

Keywords: Ozonolysis, Bubble Reactor, Waste Cooking Oil, Bio Jet, Esterification

(C) RASĀYAN. All rights reserved

\section{INTRODUCTION}

The production of alternative renewable clean hydrocarbon fuels or biofuels is becoming crucial due to unavoidable depletion of fossil fuel reserves, the increasing demand for fuels, the increasing concerns over the main oil-producing regions geopolitical instability, the large fuel price fluctuation, the increasing consciousness of negative environmental effect related with fossil fuels combustion, and the increasing of environmental concern due to the greenhouse gas emissions that responsible for climate change. ${ }^{1-6}$ International Energy Agency estimated that biofuels will reach for $27 \%$ usage of all fuels in the transportation field (primarily consist of biodiesel and bio jet fuel). The air travel sector (domestic, international and shipping) will contribute with $10 \%-32 \%$ of the total emissions by $2050^{5}$. Thus, the development of the alternative renewable biofuels which produce less pollution is getting an increasing concern from many researchers ${ }^{7}$. Previous research proved that biofuels can improve performance and reduce emission in diesel engine ${ }^{8}$. Another research reveals that biofuel made from pine oil can decrease the $\mathrm{CO}$ and $\mathrm{HC}$ emission in single cylinder diesel engine ${ }^{9}$.

Rasayan J. Chem., 12(2), 478-483(2019)

http://dx.doi.org/10.31788/RJC.2019.1224058

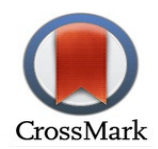


Lignocellulosic biomass, vegetable oils, sugar, starchy, and animal fatty tissues are the possible raw material for biojet fuel production. There are five pathways identified for the biojet fuel production which are depending on the raw material ${ }^{5}$. The pathways are: (i)lipids hydroprocessing, (ii) alcohol-based biofuel, (iii) biomass pyrolysis to jet, (iv) gasification of biomass followed by Fischer-Tropsch process, and (v) biomass upgrade utilizing the hydrothermal process.Biojet fuel can be generated using hydrogenesis technology and also can be produced from an oxygen-cleaved reaction of natural oil ${ }^{4}$. A splitting process of vegetable oils components with hydrogen is the definition of hydrogenases. Meanwhile, the oxygen-cleaved reaction can be performed by ozonolysis or oxidative cleavage. The common synthetic method applied in the cleavage of unsaturated carbon-carbon bond is the ozonolysis in which replaced with a double bond to oxygen. The major advantages of this method are less polluting and a higher selectivity can be achieved ${ }^{10}$. The ozonolysis products are the ozonide and aldehyde or the keton on the alkene of uncleavage branched. Ozonolysisprocess utilizing $\mathrm{NaOH}$ or $\mathrm{NaOCH}_{3}$ in methanol with $\mathrm{CH}_{2} \mathrm{Cl}_{2}$ as the co-solvent tend to yield a middle chain of ester which have a similar characteristic with bio jet fuel produced from fossil fuel ${ }^{10}$. Bio-jet fuel is comprised of ester fraction made from Babassu vegetable oil ${ }^{11}$. The ozonolysis of methyl ester will produce a medium chain of methyl ester having 8-16 carbon chains and that is jet fuel/bioavtur ${ }^{11}$. The unsaturated fatty acid methyl esters (FAMEs)ozonolysis in biodiesel and vegetable oils are able to produce a variation of $\mathrm{C} 3$ to $\mathrm{C} 13$ chain length of rich acid and aldehydes.

Since the medium carbon chains of methyl ester that have similarity with the bio-jet fuel can be produced from the cleavage of a long chain of methyl ester or FAME of biodiesel, thus in this present study we investigated the ozonolysis of used cooking oil-based biodiesel in a bubble ozonolysis reactor. Since the free fatty acid (FFA) of the ozonolysis product was relatively high, it was then followed by the FFA esterification process towards the ozonolysis product.

\section{Material and Methods}

\section{EXPERIMENTAL}

Materials used in this research consist of cooking oil waste-based biodiesel, aquadest, sulphuric acid, ethanol, nitrogen, kalium hydroxide, and methanol.Ozonolysis method using a bubble reactor which comprised of reaction tank, ozone generator and bubble reactor column as shown on Fig.-1.

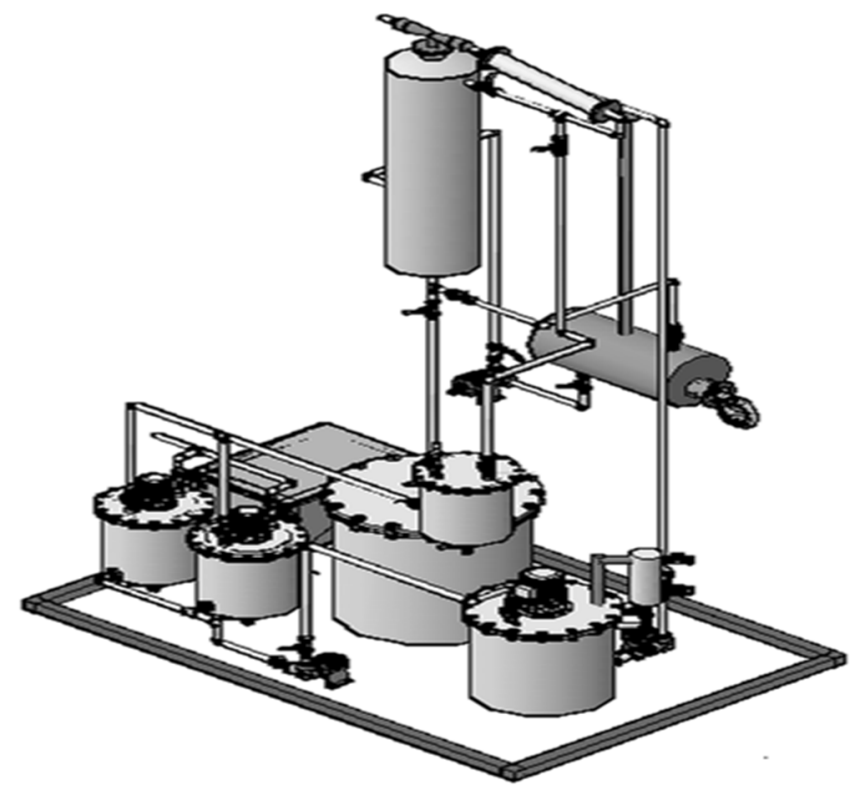

General Procedure

Fig.-1:Bubble Ozonolysis Reactor

The bubbleozonolysis reactor was fed with $25 \mathrm{~kg}$ of cooking oil waste-based biodiesel, 10-litre methanol and kalium hydroxide as the catalyst. Air and ozone mixture of 100 liters per minutes was fed to the 
reactor column. The ozone concentration was set at $34,3 \mathrm{~g} / \mathrm{m}^{3}$. Ozone concentration was monitored by Ozone Monitor Model 454. The reaction temperature was set at room temperature approximately $26^{\circ} \mathrm{C}$ in atmospheric pressure.The ozonolysis process condition was conducted as listed in the Table-1then followed by the FFA esterification process towards the ozonolysis product. FFA esterification process can be seen in Fig.-2. The esterification was set for 1 hour and $1 \%$ of the catalyst concentration. The ozonolysis product and the esterified product were analyzed for their density and kinematic viscosity. The kinematic viscosity of the samples was analyzed by using Oswald method based on ISO 3104. The viscosity determination was conducted at temperature $40^{\circ} \mathrm{C}$.

Table-1: The Process Variables of the Ozonolysis

\begin{tabular}{c|c|c|c|c}
\hline No. & Biodiesel (Litre) & Methanol (Litre) & Catalyst (\%) & Time (hour) \\
\hline 1 & 2,5 & 10 & 1 & 1 \\
\hline 2 & 2,5 & 10 & 1 & 2 \\
\hline 3 & 2,5 & 10 & 1 & 3 \\
\hline 4 & 2,5 & 10 & 3 & 1 \\
\hline 5 & 2,5 & 10 & 3 & 2 \\
\hline 6 & 2,5 & 10 & 3 & 3 \\
\hline
\end{tabular}

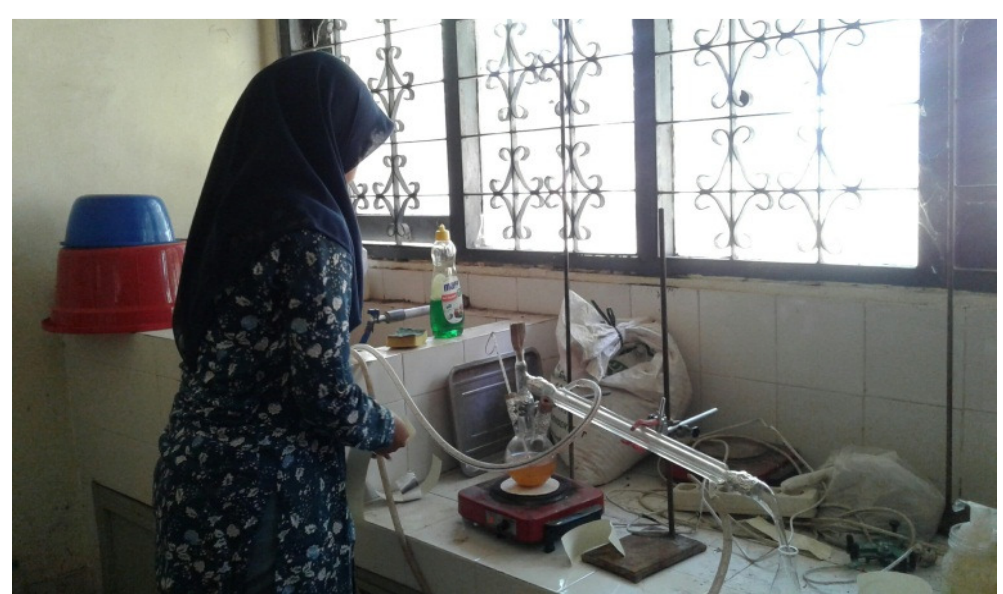

Fig.-2: FFA Esterification Process for Ozonolysis Product

\section{RESULTS AND DISCUSSION}

Cooking oil waste-based biodiesel was ozonolyzed in a bubbling ozonolysis reactor in order to build a shorter methyl ester that can be further used as bio jet fuel. After the ozonolysis process completed, it was followed by FFA esterification process towards the ozonolysis product. The esterification was set for one hour and $1 \%$ of the catalyst concentration. The ozonolysis product and esterified product was analyzed to measure density and kinematic viscosity. The density and kinematic viscosity of the ozonolysis product and the esterification product were shown on Fig.-3and Fig. -4 .

Figure-3 and Figure-4 show that the ozonolysis is capable of reducing the chain length of the methyl ester which represented by the decreasing of density and viscosity. Ozonolysis procedure which proceeds under mild conditions is a convenient and highly effective method in oxidative scission of $\mathrm{C}=\mathrm{C}$ double bonds of the used cooking oil-based biodiesel. One of the strongest oxidizing agents is Ozone $\left(\mathrm{O}_{3}\right)^{12}$. Ozone is having reduction potential $\left(\mathrm{E}^{0}\right)$ of $2.07 \mathrm{~V}$ at $25^{\circ} \mathrm{C}$ temperature. Oxygen engaged in the powerful endothermic reaction can produce ozone. Ozone decomposes easily into molecular form an atomic form of oxygen. The most common methods in obtaining ozone are utilizing a corona discharge to pass air consist of oxygen. In the corona discharge, some of the oxygen molecules are separate into oxygen atoms. The oxygen atoms will turn and blend with oxygen molecules to form ozone. It was then the ozone is used to cleavage the $\mathrm{C}=\mathrm{C}$ double bonds of the cooking oil waste-based biodiesel since the ozone molecule behaves as a dipolar ion and is highly reactive toward compounds incorporating conjugated double bonds 
RASĀYAN J. Chem.

Vol. 12 | No. 2 |478 - 483| April - June | 2019

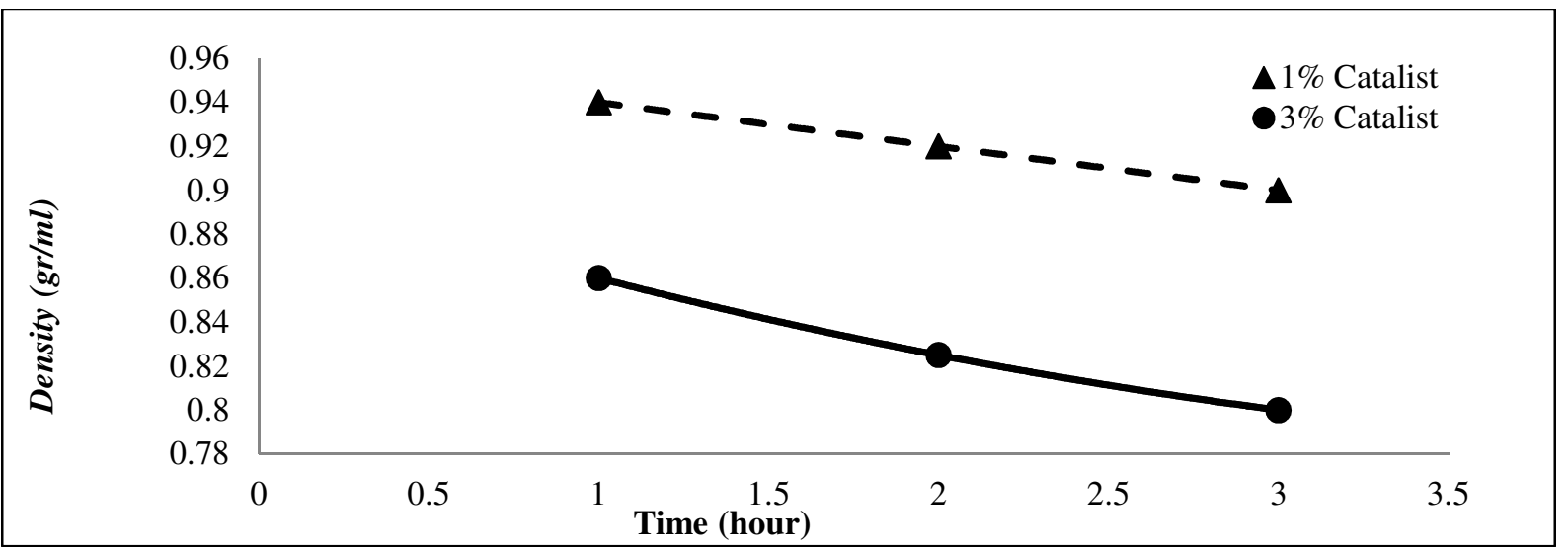

Fig.-3: The Density of the Product of the Cooking Oil Waste based Biodiesel Ozonolyzed in a Bubble Reactor

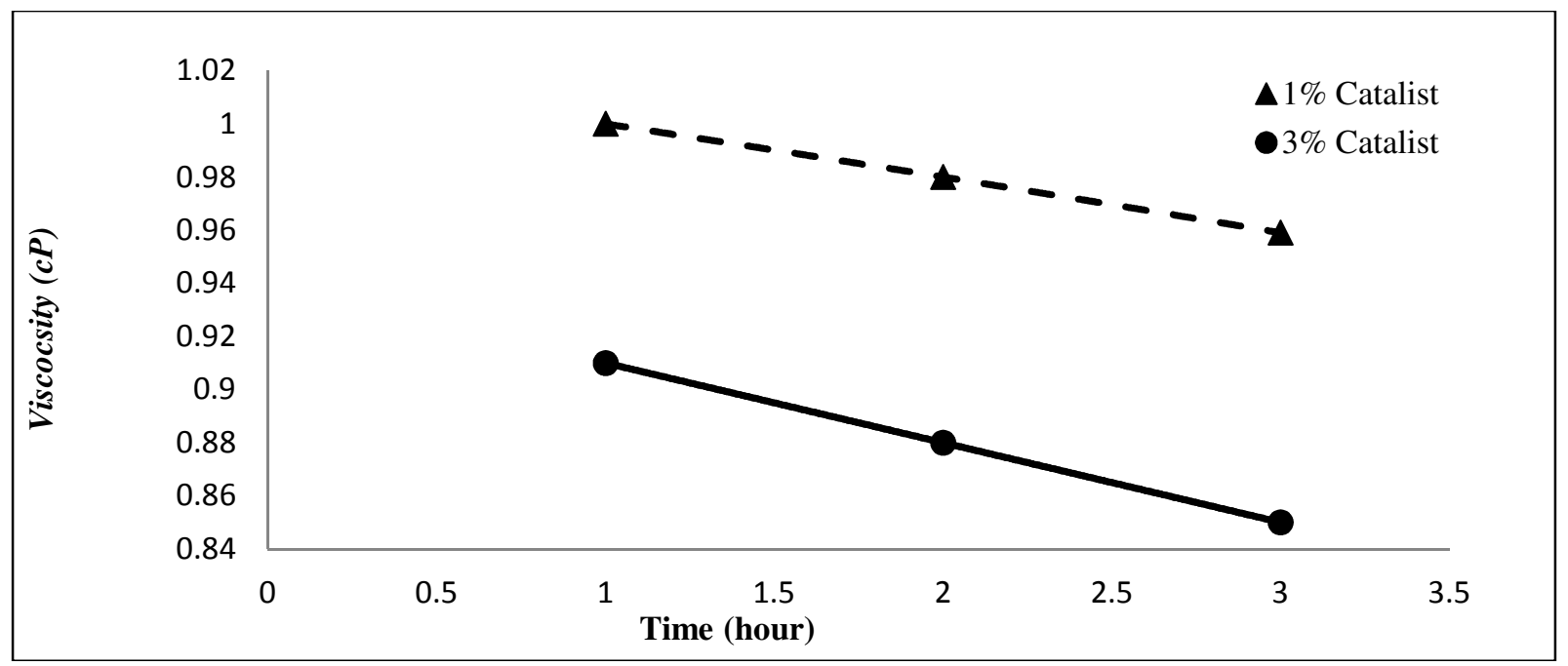

Fig.-4: The Viscosity of the Product of Cooking Oil Waste based Biodiesel Ozonolyzed in a Bubble Reactor
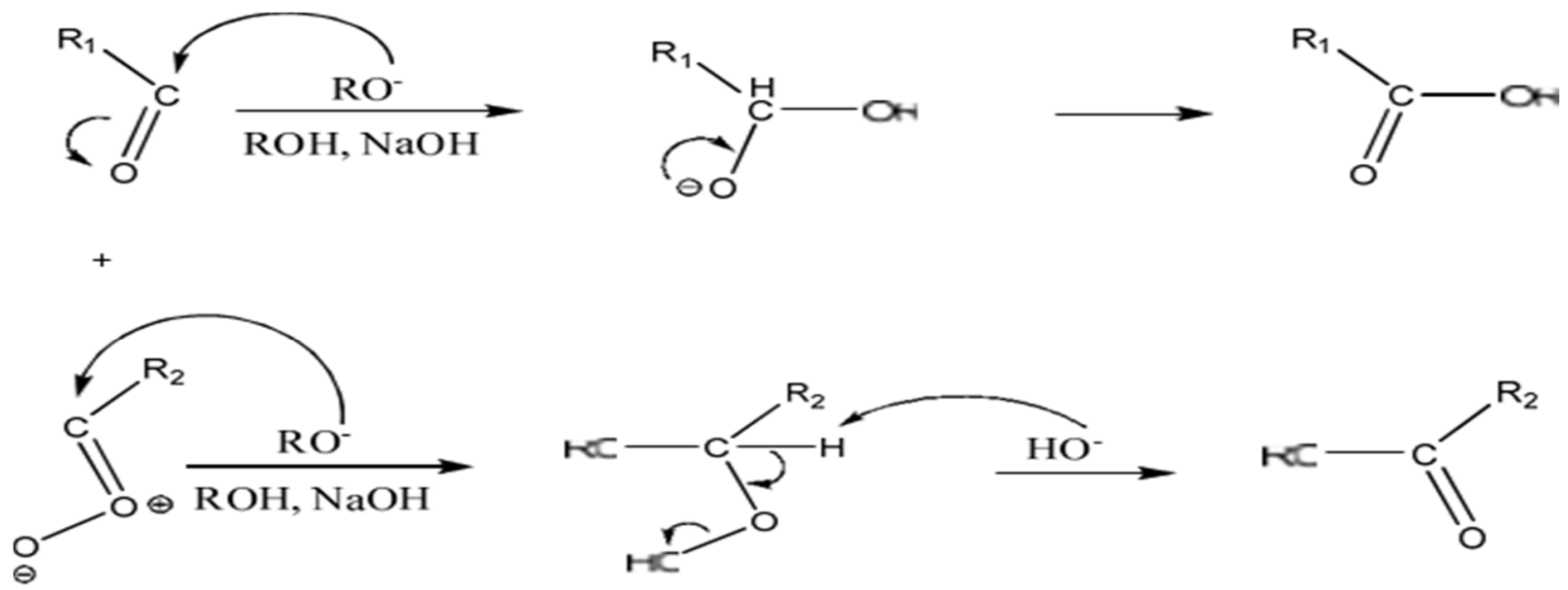

Fig.-5: The Ozonolysis Mechanism ${ }^{11}$ 
and functional groups with high electron densities. The ozonolysis of double bonds in the cooking oil waste-based biodiesel in the presence of $\mathrm{NaOH}$ in methanol can tend reaction towards the ester formation. The transformation is conducted by trapping the carbonyl oxide and aldehyde in the cleavage step then followed by the ozone oxidation of the anionic compounds as shown on the Fig-5.

Furthermore, the ozonolysis product is reported in having a high FFA content. Hence in this research, the ozonolysis product was esterified in order to convert FFA into a medium chain of methyl ester.The density and kinematic viscosity of the esterification product was shown on Fig.-6 and Fig.-7.

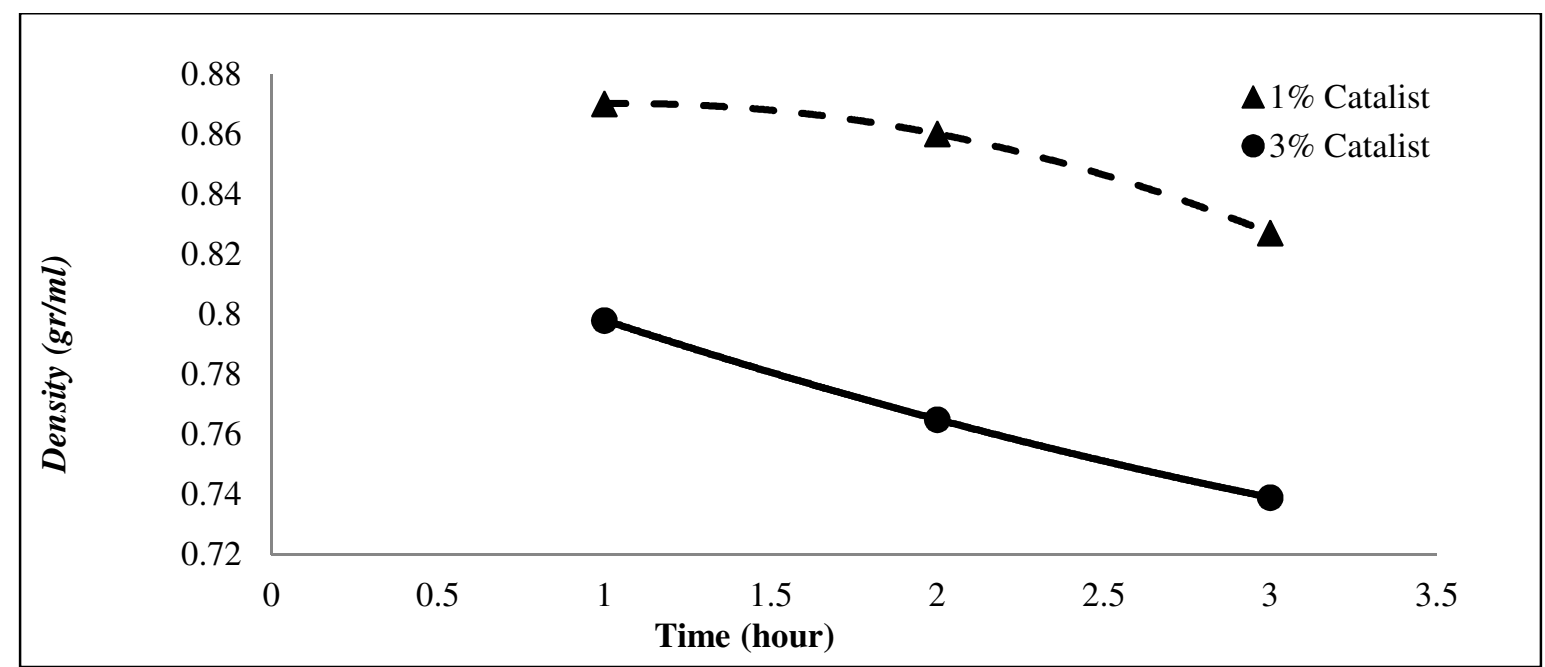

Fig.-6: The Density of the Esterification Product of the Ozonolized of Cooking Oil Waste based Biodiesel

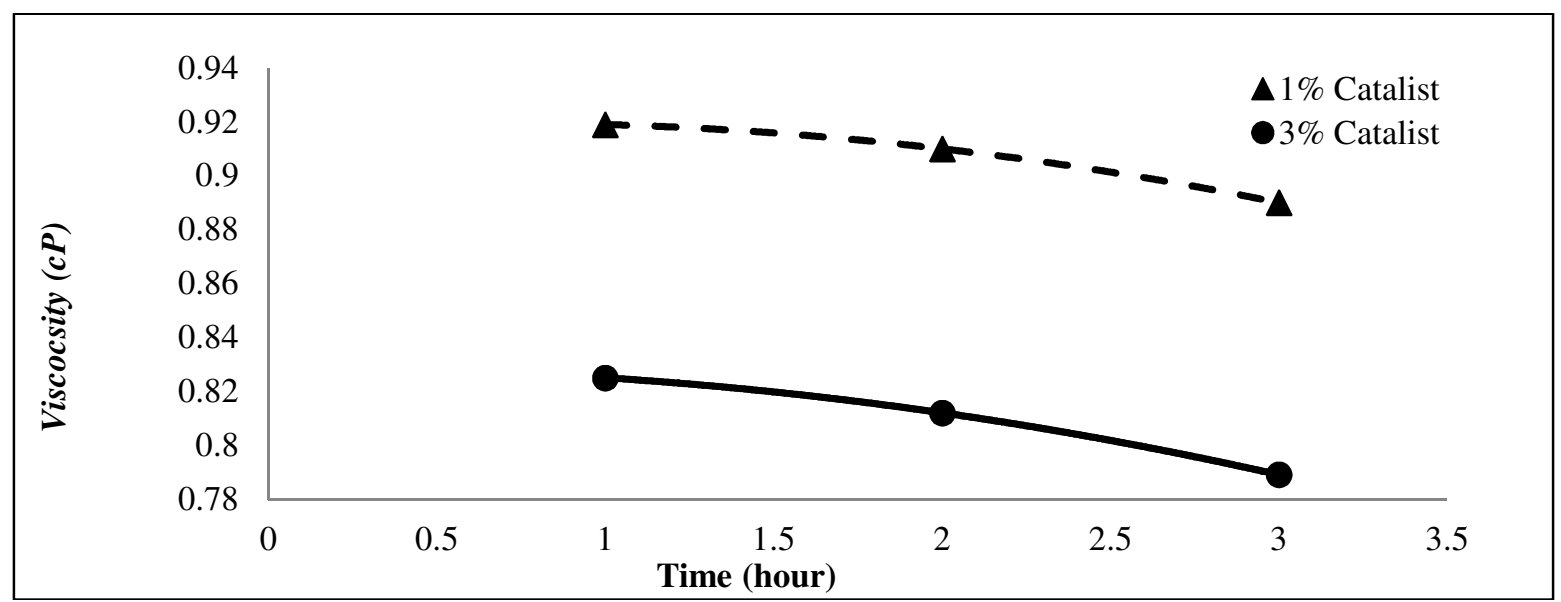

Fig.-7: The Viscosity of the Esterification Product of the Ozonolized of Cooking Oil Waste based Biodiesel

Figure-6 and Figure-7 show that some of the esterification product were met the density and kinematic viscosity of the commercial bio jet fuel. The density should be in the range of $0.775-0.840 \mathrm{~g} / \mathrm{ml}$ for Jet A1 according to ASTM D1655-04a, IATA, def Stand 91-91, ASTM D7566 ${ }^{13}$.The kinematic viscosity of Jet A-1 must be in range $0.8-0.88 \mathrm{Cp}^{13}$. The density of the ozonized product conducted at 2 and 3 hours with $3 \%$ of catalyst addition was able to give a product having a density of $0.8 \mathrm{~g} / \mathrm{ml}$ to $0.825 \mathrm{~g} / \mathrm{ml}$. Meanwhile of the esterified of the ozonized product of 1-3 hours ozonolysis and 3\% catalyst addition were in the range of $0.738 \mathrm{Cpto} 0.826 \mathrm{Cp}$.

\section{CONCLUSION}

Cooking oil waste as ozonolysis raw material was being fed into the bubble reactor and the ozonolysis experiment carried out in different parameters. Those parameters are catalyst amount of variation range between $1 \%$ to $3 \%$ and ozonolysis time which ranges from 1 hour to 3 hours. 


\section{RASĀYAN J. Chem.}

Vol. 12 | No. 2 |478 - 483| April - June | 2019

- The density of ozonolysis product then being analyzed and measure which results in $0.9 \mathrm{~g} / \mathrm{ml}$ to 0.94 $\mathrm{g} / \mathrm{ml}$ with $1 \%$ catalyst and $0.8 \mathrm{~g} / \mathrm{ml}$ to $0.86 \mathrm{~g} / \mathrm{ml}$ with $3 \%$ catalyst. The ozonolysis product is not meet the Jet A-1 density criteria which $0.775-0.840 \mathrm{~g} / \mathrm{ml}$. In order to meet the criteria, the esterification process was conducted. The density of esterification product was reported in range $0.8 \mathrm{~g} / \mathrm{ml}$ to 0.825 $\mathrm{g} / \mathrm{ml}$ and can be concluded that the final product of cooking oil waste is meet the density criteria of Jet A-1 fuel.

- The kinematic viscosity of ozonolysis product show range between $0.96 \mathrm{Cp}$ to $1 \mathrm{Cp}$ for $1 \%$ catalyst and $0.86 \mathrm{Cp}$ to $0.91 \mathrm{Cp}$ with $3 \%$ catalyst. Jet $\mathrm{A}-1$ criteria for kinematic viscosity is in a range of 0.8 $\mathrm{Cp}-0.88 \mathrm{Cp}$. The ozonolysis product has not met the Jet A-1 criteria. Esterification process of ozonolysis product helps the final product to meet the Jet A-1 criteria. After being esterified the kinematic viscosity of the final product result in a range of $0.738 \mathrm{Cpto} 0.826 \mathrm{Cp}$.

- The last conclusion is the ozonolysis and esterification experiment conducted by researcher proven to produce a final product which meets the Jet A-1 criteria as jet fuel.

\section{REFERENCES}

1. R. S. Boyas, F. Trejo-Zarraga, F. D. Hernández-Loyo, 2012; Hydroconversion of triglycerides into green liquid fuels, in: Iyad Karame (Eds), Hydrogenation, E-Publishing., InTech Open. pp. 187-190. DOI: $10.5772 / 48710$

2. R. Travaini, J. Martin-Juarez, A. Lorenzo-Hernando, S. Balado-Rodriguez, Bioresource Technology, 199, 2(2016), DOI:10.1016/j.biortech.2015.08.143

3. W. C. Wang, L. Tao, J. Markham, Y. Zhang, E. Tan, L. Batan, E. Warner, M. Biddy, Renewable and Sustainable Energy Reviews, 53,801(2016), DOI:10.2172/1278318

4. R. Laksmono, A. Datumaya and Z. Abidin, Jurnal Pertahanan, 2(3), 243(2016), DOI: $10.33172 /$ jp.v2i3.102

5. C. Gutiérrez-Antonio, F. I. Gómez-Castro, J. A. de Lira-Flores, S. Hernández, Renewable and Sustainable Energy Reviews,79(C),709(2017), DOI:10.1016/j.rser.2017.05.108

6. N. T. Truong and A. Boontawan, International Journal of Chemical Engineering And Applications, 8 (3),153(2017), DOI: 10.18178/ijcea.2017.8.3.648

7. M. Saravanakumar, Prabhahar, Sangeetha Krishnamoorthi and S. Sendilvelan, Rasayan J. Chem., 11(1), 372(2018), DOI:10.7324/RJC.2018.1112024

8. S. Sendilvelan and K. Bhaskar, Rasayan J. Chem., 10(3), 1048(2017), DOI: 10.7324/RJC.2017.1031703

9. S. Nallusamy, S. Sendilvelan, K. Bhaskar and N. Manikanda Prabu, Rasayan J. Chem., 10(3), 879(2017), DOI:10.7324/RJC.2017.1031787

10. C. Gutiérrez-Antonio, A. G. Romero-Izquierdo, F. I. Gómez-Castro, S. Hernández, A. BrionesRamírez, Chemical Engineering and Processing: Process Intensification, 110, 134(2016), DOI:10.1016/j.cep.2016.10.007

11. Paula Y. Bruice, Organic Chemisty, 4th ed. Prentice-Hall, New York,(2004), DOI: 10.1021/ed073pA92.2

12. James A. Marshall and Albert W. Garofalo, J. Org. Chem, 58(14), 3675(1993), DOI:10.1021/jo00066a019

13. S. Blakey, L. Rye, C. W. Wilson, Proceedings of Combustion Institute, 33(2), 2863(2011), DOI:10.1016/j.proci.2010.09.011

[RJC-4058/2018] 